\title{
The dawn and dusk electrojet response to substorm onset
}

\author{
E. Borälv ${ }^{1}$, P. Eglitis ${ }^{1}$, H. J. Opgenoorth ${ }^{1,2}$, E. Donovan ${ }^{3}$, G. Reeves ${ }^{4}$, P. Stauning ${ }^{5}$ \\ ${ }_{1}^{1}$ Swedish Institute of Space Physics, Box 537, S-751 21 Uppsala, Sweden \\ ${ }^{2}$ Finnish Meteorological Institute, Geophysical Research, P.O. Box 503, FIN-00101 Helsinki, Finland \\ ${ }^{3}$ Department of Physics and Astronomy, University of Calgary, Calgary, Alberta, Canada T2N 1N4 \\ ${ }^{4}$ Los Alamos National Laboratory, Mail Stop D-436, NM 87545, USA \\ ${ }^{5}$ Solar-Terrestrial Physics Division, Danish Meterological Institute, Lyngbyvej 100, DK-2100 Copenhagen, Denmark
}

Received: 1 March 2000 / Revised: 19 June 2000 / Accepted: 19 June 2000

\begin{abstract}
We have investigated the time delay between substorm onset and related reactions in the dawn and dusk ionospheric electrojets, clearly separated from the nightside located substorm current wedge by several hours in MLT. We looked for substorm onsets occurring over Greenland, where the onset was identified by a LANL satellite and DMI magnetometers located on Greenland. With this setup the MARIA magnetometer network was located at dusk, monitoring the eastward electrojet, and the IMAGE chain at dawn, for the westward jet. In the first few minutes following substorm onset, sudden enhancements of the electrojets were identified by looking for rapid changes in magnetograms. These results show that the speed of information transfer between the region of onset and the dawn and dusk ionosphere is very high. A number of events where the reaction seemed to preceed the onset were explained by either unfavorable instrument locations, preventing proper onset timing, or by the inner magnetosphere's reaction to the Earthward fast flows from the near-Earth neutral line model. Case studies with ionospheric coherent (SuperDARN) and incoherent (EISCAT) radars have been performed to see whether a convectioninduced electric field or enhanced conductivity is the main agent for the reactions in the electrojets. The results indicate an imposed electric field enhancement.
\end{abstract}

Key words: Ionosphere (auroral ionosphere; electric fields and currents) - Magnetospheric physics (storms and substorms)

\section{Introduction}

The horizontal ionospheric currents are usually divided into the global convection (auroral) electrojets and the

Correspondence to: E. Borälv

e-mail: eb@irfu.se more localized substorm current wedge. The convection electrojets are believed to be controlled mainly by the electric field resulting from the convection in the magnetosphere (Kamide and Kroehl, 1994), and originate at local noon, flowing westward and eastward in two jets along the auroral oval to midnight. They move towards to the magnetosphere via field-aligned currents.

While the convection electrojets are always present, the westward directed substorm current wedge is a superposed current system during the expansion phase of the substorm. It is initially localized in a longitudinally limited region of the nightside ionosphere and then expands mainly azimuthally and poleward. The substorm current wedge is created by enhanced conductivity due to particle precipitation (Kamide and Kokobun, 1996).

Most studies of substorm phenomena involve consideration of observations within the context of one or both of the modified near-Earth neutral line (NENL) model (Baker et al., 1996) sometimes called the "pileup" model (Shiokawa et al., 1998 and references therein), and the current disruption (CD) model (Lui, 1996). According to the NENL model, substorm onset takes place $20-30 \mathrm{R}_{E}$ down-tail, by reconnection that produces Earthward fast flows (Baker et al., 1998). When the flows encounter the more dipole-like magnetic field in the near-Earth tail they slow down and divert around the "obstacle". This produces electric fields and vortical flows which in turn can trigger the substorm current disruption (Reeves, 1998, Shiokawa et al., 1998). Also, this braking produces a compressional pulse that can energize particles and transport them Earthward, to be detected as particle injections at substorm onset. It has been suggested lately though, that the tail current disruption could be a unique process, and the near-Earth reconnection process only sets up favorable conditions for triggering the disruption (Ohtani et al., 1999).

The CD model predicts the substorm current wedge to develop as a result of an instability in the cross-tail current. In this model, the primary onset location is closer to Earth, at about $10 \mathrm{R}_{E}$, from which a rarefaction wave propagates tailward to produce a neutral line. 
A magnetic substorm is divided into three phases; the growth, expansion and recovery (Rostoker, 1996). The growth phase involves storage of solar wind energy in the magnetosphere due to the increased rate of reconnection at the subsolar magnetopause, and the tail therefore adopts a more outstretched shape. The loading of energy is visible at ground-based magnetometer stations as a slow gradient change in the magnetograms, indicative of increases of the electrojets due to the enhanced cross-polar cap convection. Another sign is that the electrojets move equatorward during this phase, as the polar cap expands.

The substorm expansion phase starts with the onset, which can be detected by substorm indicators, such as Pi2 pulsations, magnetic bays due to the substorm current wedge, auroral activity and particle injections at geosynchronous orbit. In the expansion phase the energy stored in the magnetosphere during the growth phase is released in various ways (Kamide and Baumjohann, 1993); by plasmoid release, plasma sheet heating, ring current injection, particle precipitation and Joule heating in the ionosphere. At onset the electrojets make a poleward leap as the polar cap regains its size. Usually it is only the westward electrojet system which is considered to intensify at onset, due to the superposition of the substorm current wedge. In the recovery phase the convection electrojets slowly return to normal strength.

Observational work by Grafe et al. (1987) (also several unpublished manuscripts) and Opgenoorth and Pellinen (1998) has elucidated some as yet uninvestigated processes that influence the convection electrojets at substorm onset. They discovered that the eastward electrojet over Scandinavia experienced strong and immediate intensifications at onset, apart from the slow increase during the growth phase.

The questions to be adressed here are, if there indeed are very fast responses in the dawn- and dusk electrojets to a substorm onset at magnetic midnight, what is the cause for these reactions? Are they controlled by imposed electric fields or by conductivity enhancements from precipitating particles?

The aim of this substorm study was to answer these questions by investigating the time delay between a near magnetic midnight onset and any reactions in the dawn and dusk electrojets, clearly separated from the nightside located substorm current wedge. The reaction was also to be distinguished from the more slowly increasing strength of the currents during the growth phase of the substorm. If any responses could be found, their cause would be further investigated with the help of data from coherent and incoherent scatter radars.

\section{Instruments and data sets}

The task was best achieved by looking at substorm onsets occurring over Greenland. At the southern tip of Greenland local magnetic midnight occurs at approximately 02:00 UT, so the time interval of 02:00-04:00 UT was selected in order to use onsets slightly to the west of Greenland as well. Substorm onset timing was performed by looking at the Los Alamos National Laboratory (LANL) 1991-080 satellite, which crosses magnetic midnight at roughly 23:00 UT. At times when no satellite data was available, data from a magnetometer station, part of the Danish Meteorological Institute (DMI) magnetometer network on Greenland, Narssarssuaq (NAQ), was searched for onsets. NAQ was also used to confirm that the injections seen were truly related to substorm onsets. For cases when NAQ was not located directly underneath the substorm current wedge, data from other DMI stations on Greenland was also examined.

For this UT interval the Canadian MARIA magnetometer network was located in the evening sector, recording the eastward electrojet. On the morning side, separated by almost $180^{\circ}$ in longitude, was the IMAGE magnetometer chain monitoring the westward electrojet. The locations of all these instruments are illustrated in Fig. 1. The total data set investigated comprised 458 days between October 1997 and January 1999.

The LANL satellite data base provides information about the radiation environment at geostationary orbit, i.e., at approximately $6.6 \mathrm{R}_{E}$. The satellite employed in this study, 1991-080, is equipped with a synchronous orbit particle analyser (SOPA) instrument (Reeves et al., 1996b), which measures electron energy fluxes over the energy range $50 \mathrm{keV}$ to about $26 \mathrm{MeV}$. It was placed in orbit in the equatorial plane at approximately $10^{\circ}$ east (geographic longitude), meaning that it had magnetic midnight at about 23:00 UT, and would record the injected electrons drifting eastward after an onset over Greenland. In order to be able to use EISCAT data in the dusk sector we also present an event where we used another SOPA-carrying LANL satellite, 1994-084, which was placed over Russia at a longitude of about $105^{\circ}$ east, recording midnight sector substorm activity after 14:00 UT. In the satellite data we studied low-energy electron flux (five channels; 50 to $315 \mathrm{keV}$ ). We looked for near-dispersionless injections, and picked the time for the flux increase of the $315 \mathrm{keV}$-energy channel as the onset time. This does of course lead to an error, the chosen onset time being somewhat later than the true onset, since we do not account for the dispersions. We estimate the error in this to be on the time scale of a minute, since we are dealing with near-dispersionless injections. The onset times found were compared with the times determined from the DMI magnetometers. If the onset was more easily distinguished in the magnetometer data, this was used instead to define the onset time. The time resolution for the LANL data is $10 \mathrm{~s}$, and it has been plotted as low-energy electron flux on a semilogarithmic scale.

The Danish Meteorological Institute has a network of magnetometers on Greenland, some of them participating in the INTErnational Real-time MAGnetic observatory NETwork (INTERMAGNET). In this study mainly one station has been used to determine the onset time, Narssarssuaq (NAQ), located on the 


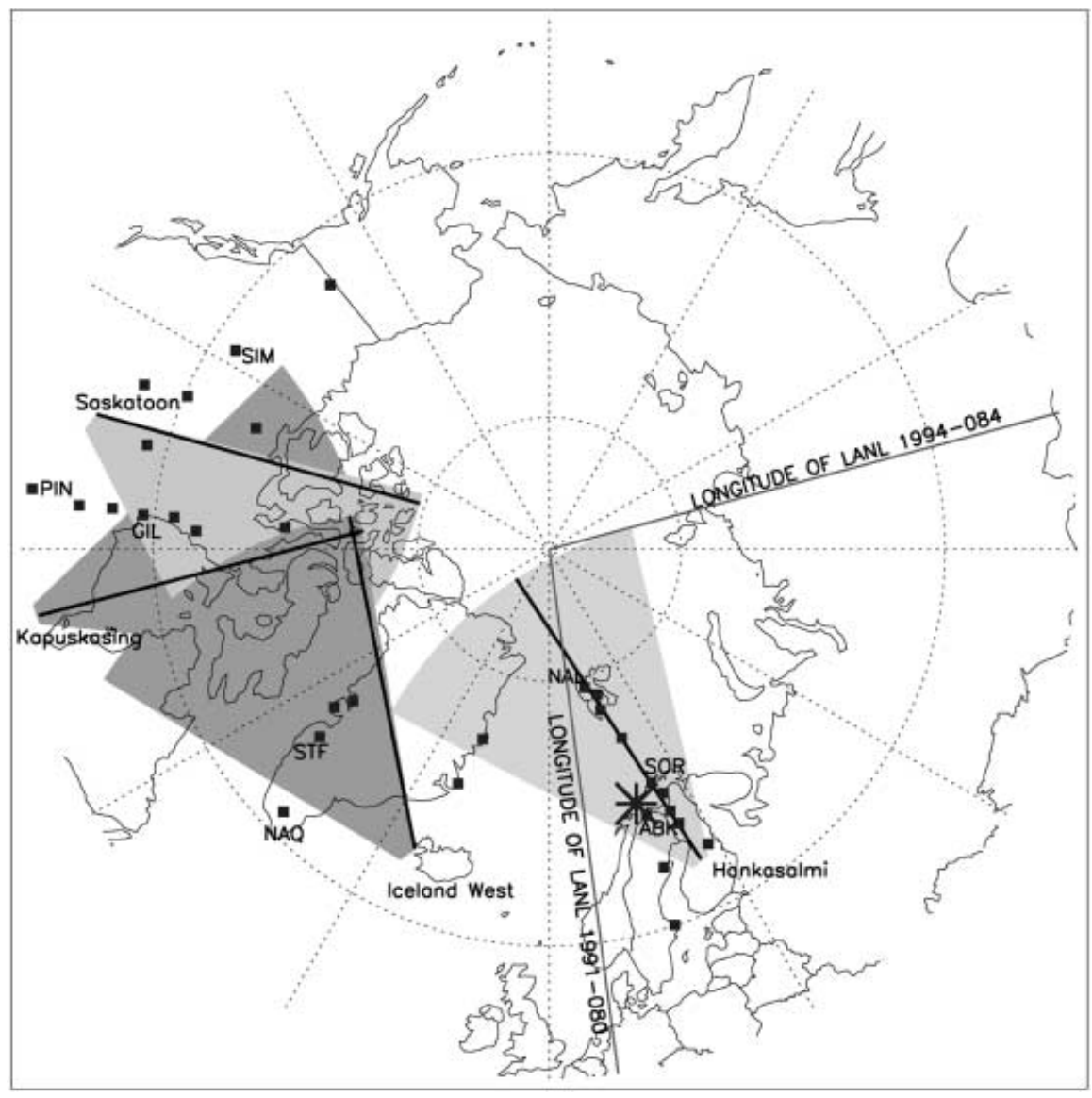

Fig. 1. Location of instruments. Magnetometer networks shown are MARIA in Canada, IMAGE in Scandinavia and DMI magnetometers on Greenland. The SuperDARN radars' field-of-view and EISCAT Tromsø (asterisk) are also displayed. Geostationary satellite positions are depicted by longitudinal lines southern tip of Greenland. For magnetic disturbances measured on the ground we use the coordinate system defined by $x$ being positive towards magnetic (geographic for MARIA and IMAGE) north, $y$ towards magnetic (geographic) east, and $z$ pointing downwards into the Earth. To decide whether an onset occurred over Greenland we searched for negative bays of at least 200-300 nT in the $x$-component. By examining also the $y$ - and $z$-components of the magnetic field we could achieve a valid onset timing, since simultaneous deviations in both $x$ - and $z$-components makes it reasonable to assume that the substorm current wedge appeared at that specific time (Opgenoorth et al., 1980). In that case the estimated error in determination of onset time would be about a minute. The time resolution for DMI data is $20 \mathrm{~s}$ and it has been plotted as deviations from a quiet time value.

The International Monitor for Auroral Geomagnetic Effects (IMAGE) is the magnetometer array in the Scandinavian Magnetometers-Ionospheric Radars-Allsky Cameras Large Experiment (MIRACLE) network (Lühr et al., 1998; Syrjäsuo et al., 1998). IMAGE consist of 22 magnetometer stations covering geographic latitudes from 60 to $79^{\circ}$. For the UT interval described, 02:00-04:00 UT, IMAGE was located on the dawnside, underneath the westward convection electrojet. To see enhancements in the jet, we searched for sharp negative bays in the $x$-component magnetometer data. The time resolution for the IMAGE data is $10 \mathrm{~s}$. We have plotted
IMAGE magnetometer data as deviation from the mean value in the time interval 00:00-06:00 UT.

The CANOPUS (Canadian Auroral Network for the OPEN Program Unified Study) instrument array includes a magnetometer/riometer array called MARIA (Rostoker et al., 1995). MARIA consists of 13 stations in Canada, located in an H-shape, with two longitudinal lines at approximately 336 and $313^{\circ}$ magnetic longitude, and a latitudinal line at approximately $67^{\circ}$ magnetic latitude. Since MARIA was located at dusk in this study, under the eastward electrojet, we searched for positive disturbances in the $x$-component of the magnetic field. The time resolution for the MARIA data is $5 \mathrm{~s}$ and it has been plotted as deviations from the median value of the entire UT-day, i.e., the interval 00:00-24:00 UT.

For the reactions in IMAGE or MARIA, no definite restrictions were applied to the disturbance size. Anything down to a few tens of $\mathrm{nT}$ was considered to be of interest. The important observation was a simultaneous reaction in several stations for each network, as we would expect for large-scale phenomena. Using different baselines for the different magnetometer networks did not pose a problem in this case, since we were interested in rapid changes in the magnetograms and not absolute values of the magnetic field. We were certain to distinguish the convection electrojet system from the substorm current wedge because of the separation of instrument networks. According to Opgenoorth et al. 
(1980) the initial substorm current wedge is about $2000 \mathrm{~km}$ wide, and since we looked for onsets close to magneic midnight the wedge should therefore not be extended to the dawn and dusk sectors.

Increases of the electrojets due to changing electric fields or conductivity cannot be distinguished by magnetometers, whereas incoherent and coherent scatter radars are suitable instruments for this task. The coherent HF-radar system Super Dual Auroral Radar Network (SuperDARN) (Greenwald et al., 1995) can provide information about the convection pattern. The extended radar coverage in MLT and magnetic latitude facilitates studies of large-scale phenomena.

The European Incoherent Scatter (EISCAT) radar (Folkestad et al., 1983) makes localized and detailed measurements about both the electric field and the conductivity enhancement due to precipitation, in that sense being an indispensible tool for this study. For both radar systems we have used 1-min. resolution for their respective data.

\section{Observations}

We present two examples and the statistical results from the initial magnetometer study, where we identified onset responses in the dawn and dusk electrojets. We then present two additional events utilizing radar data, to try to establish what could be the cause for these electrojet reactions.

\subsection{Initial magnetometer - Satellite study}

The first four panels in each plot, showing low-energy electron flux measured by LANL 1991-080 and DMI $x$-, $y$ - and $z$-component magnetograms, are used to determine the substorm onset time. In the two lower panels IMAGE and MARIA station magnetograms from the dawn and dusk sectors are displayed.

In the first example, Fig. 2, the onset time was determined to be 02:54 UT. As it is a near-dispersionless injection, and the DMI magnetometer records a distinct onset of overhead currents in both $x$ - and $z$-components, we conclude that the timing of this onset is accurate. The fifth panel displays the reaction in IMAGE station $\mathrm{Ny}$ Alesund (NAL) at dawn, and the bottom panel shows MARIA's Fort Simpson (SIM) at dusk. At the time of onset, both NAL and SIM show small, but clear gradient changes, indicating sudden enhancements of the convection electrojets above. The reaction in NAL occurs within a minute after the onset, the one in SIM actually preceeds the onset by almost two minutes.

The onset in the second example, Fig. 3, as determined by satellite and NAQ, was at $02: 23$ UT. In the NAQ $y$-component pulsations begin and in the $z$-component a positive spike is visible, which is indicative of more distant ionospheric currents. The onset has simultaneous reactions in the magnetograms of IMAGE's Sørøya (SOR) and MARIA's Pinawa (PIN). The reactions at dawn and dusk are simultaneous, and occur
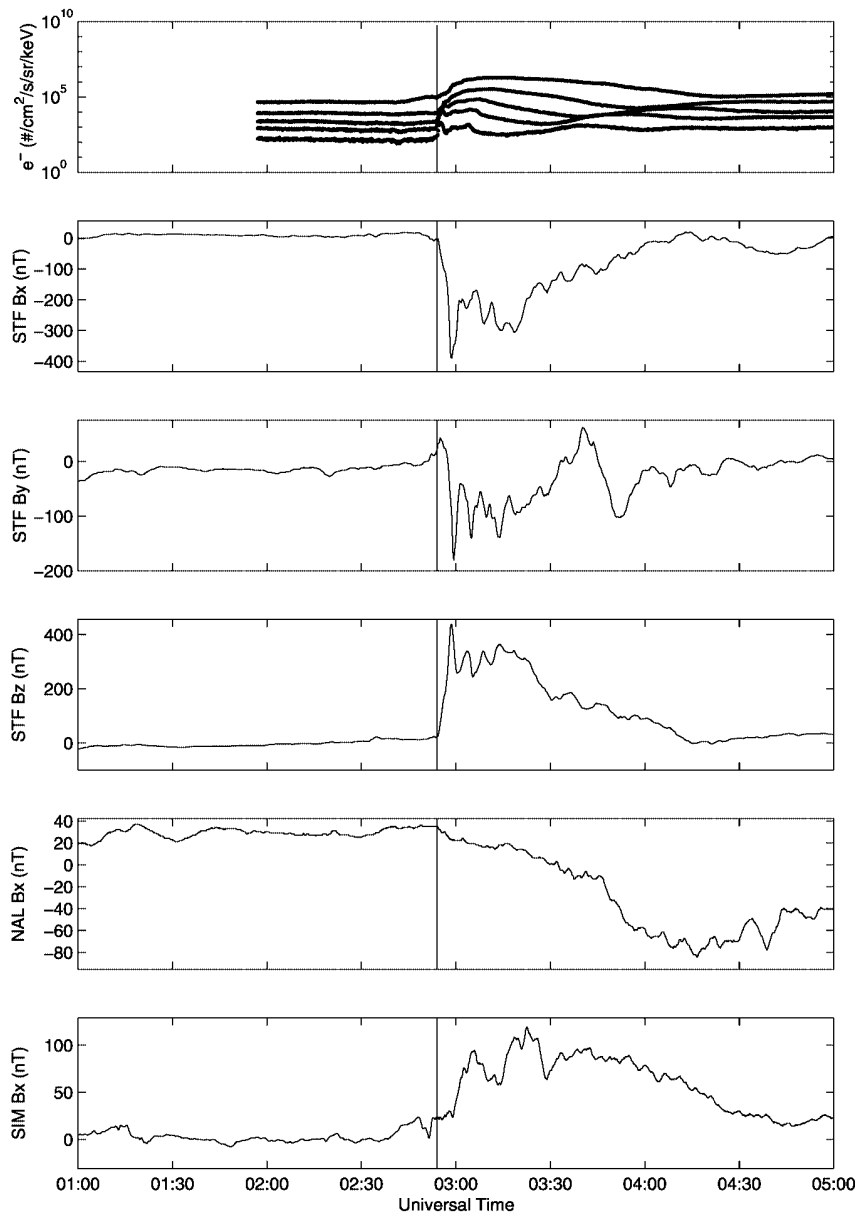

Fig. 2. January 61998 . Onset time $02: 54$ UT, marked by the line in all panels. Reactions in NAL 02:55 and SIM 02:52 UT

within half a minute after the onset. Note how the major disturbances are delayed by up to $20 \mathrm{~min}$.

Of the 458 days examined we found 50 examples suitable for this study. They were chosen on the basis that they showed a clear onset between 02:00 and 04:00 UT, either in LANL particle data or in DMI magnetograms. We looked for reactions in IMAGE and MARIA that were simultaneous for a number of stations in either network, and no restrictions were imposed on the size of the disturbance. IMAGE and MARIA were examined separately, to detect any difference in dawn and dusk response. For IMAGE there were four events in the 50 selected where we could not distinguish any reactions to onset. For MARIA the corresponding number was also four. The responselacking days were found to comprise multiple onsets and therefore difficult to interpret. In consequence, those days were not included in the statistical analysis summorised in the histograms in Fig. 4a, b.

Of interest here are reactions that occur well within $4 \mathrm{~min}$; $4 \mathrm{~min}$ is the lower limit of the time it could take for information to propagate from the onset region to the dawn and dusk electrojets through any mechanisms involving spreading of information from the nightside ionosphere to the dawn and dusk sectors. This will be 

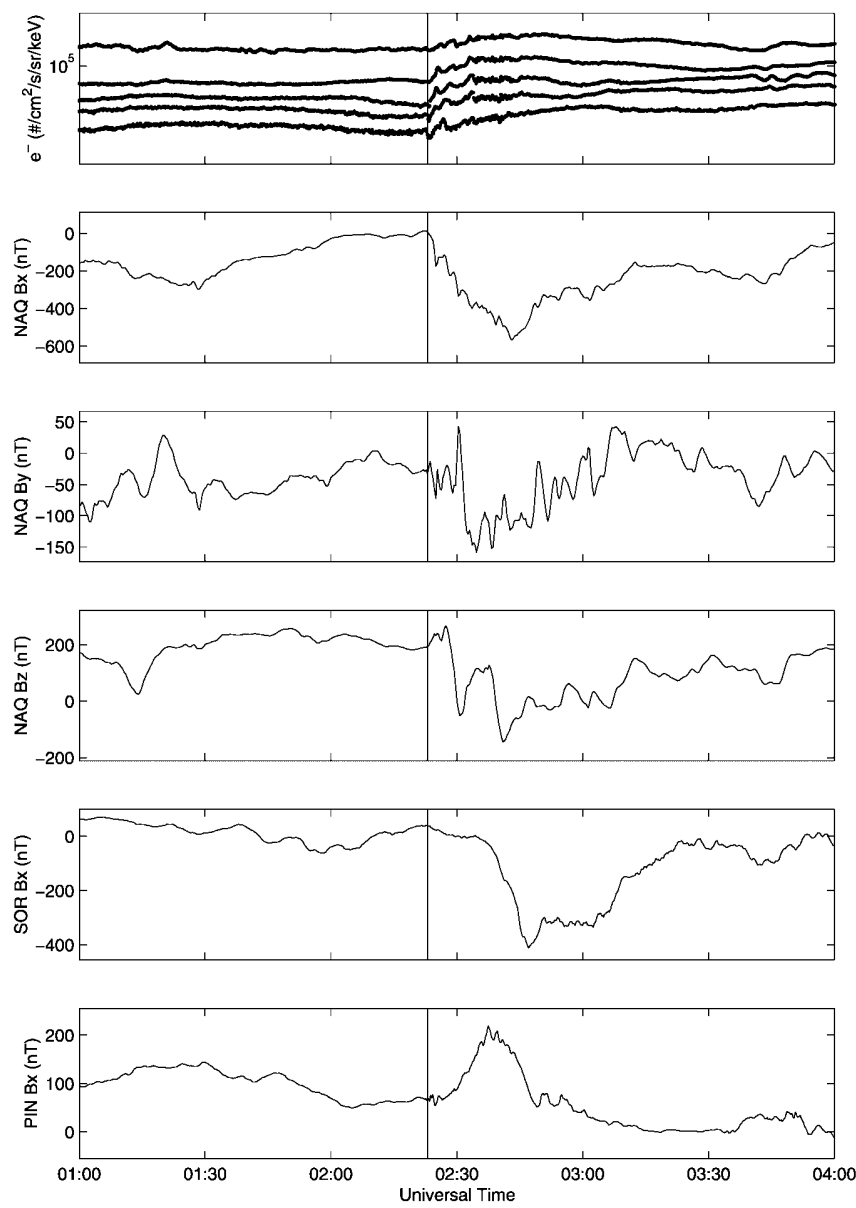

Fig. 3. June 7 1998. Onset time 02:23 UT, marked by the line in all panels. Reactions in SOR 02:23 and PIN 02:23 UT

further treated in the discussion section. Another noticable feature in the histograms are cases with negative time delays between the onset and reactions, that is, the reaction seems to precede the onset. The negative delays may arise due to errors in onset time determination, and for some events we believe that the locations of the instruments have restricted the timing of exact onsets. Nevertheless, we can find examples where the onset time has been accurately determined, still showing negative time delays. In the discussion section we will show that this feature does not have to be inconsistent, but could be explained by the Earthward fast flows of the NENL model.

\subsection{Radar studies}

As mentioned in the instrument section, magnetometers cannot distinguish between ionospheric current enhancements arising due to increased conductivity or electric field. Thus we study data from both coherent and incoherent scatter radars during similar events.

Figure 5a shows a substorm onset identified by the NAQ magnetometer. We will here concentrate on the first large negative deviation in the magnetic $x$-component, marked by the line at 03:05 UT. At this time, reactions at dawn and dusk were monitored by
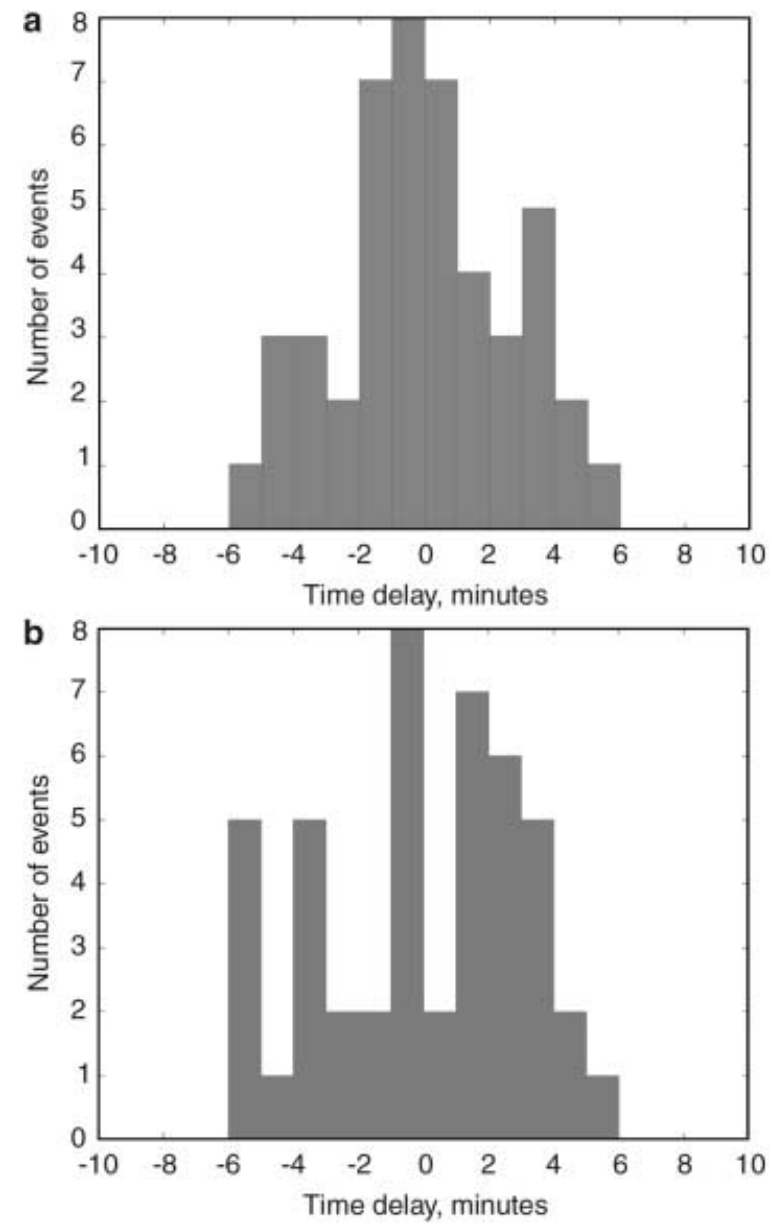

Fig. 4. a Histogram of time delay between onset and reaction at dawn. Based on measurements by LANL 1991-080 and IMAGE. b Histogram of time delay between onset and reaction at dusk. Based on measurements by LANL 1991-080 and MARIA

IMAGE's Abisko (ABK) and MARIA's Gillam (GIL). ABK registered a negative deflection from an enhancement of the westward electrojet, and simultaneously GIL recorded a positive kick, as a result of an increase of the eastward electrojet.

In Fig. 5b-e, showing stacked time series plots of line-of-sight drift velocity measured by SuperDARN, the horizontal dotted lines specify the zero line-of-sight velocity level for each range gate from 0 to 69 (bottom to top), except for CUTLASS Finland in Fig. 5e, where ranges are according to figure caption.

Figure $5 \mathrm{~b}$ shows beam 15 of Iceland West looking over Greenland. The backscatter disappears completely at the time of the onset. The explanation for this is that precipitating particles associated with the substorm current wedge change the electron density in the fieldof-view of the radar, altering either the ray propagation path, absorbing the HF-signal, or modifying the whole flow. In any case a significant change occurs at substorm onset and results in a total loss of HF radar backscatter.

The SuperDARN radars at dusk show either a sudden change in location or enhancement of the convection (Kapuskasing, Fig. 5c) or newly appearing scatter (Saskatoon, Fig. 5d). The dawnside, here 
monitored by CUTLASS Finland, Fig. 5e, is more difficult to analyze since it has been already affected by the nighttime auroral influence, and the radar data is already quite disturbed. Some increases in flow velocity become apparent after 03:05 UT, though.

The velocity enhancement in already existing backscatter in SuperDARN data suggest an enhanced electric field as the agent for the reactions at dawn and dusk. It is not possible, however, to exclude the involvement of particle precipitation as well, especially when there is a change of scatter location or newly appearing scatter. This question can best be addressed by including incoherent scatter radar information, i.e., using EISCAT.

Since there were no suitable EISCAT examples in our initial dawn-dusk study, we here choose to present an event that does not have an onset over Greenland, but over Russia, placing EISCAT in the dusk sector. For this event the onset was determined by another LANL satellite, 1994-084, placed over Russia at a longitude of about $105^{\circ} \mathrm{E}$. The injection at substorm onset, marked at 14:20 UT in the top panel in Fig. 6, is followed by several intensifications. In this case, with EISCAT located at dusk, local time about 16 MLT, we can examine the electron density and electron/ion temperatures to draw conclusions about at least the duskside reaction to substorm onset. The three lower panels in Fig. 6 show electron density and electron/ion temperatures up to $450 \mathrm{~km}$ altitude, as measured by EISCAT UHF, Tromsø (pointing field-aligned, cp1-k mode). At the time of onset, 14:20 UT, the ion temperature clearly increases, indicating an enhanced electric field. Particle precipitation, resulting in enhanced conductivity, is clearly evident in the data at 14:39 UT, roughly $20 \mathrm{~min}$ after the initial onset time. Also, the electron temperature gives an indication that particle precipitation is delayed and not involved at onset, since there is no clear increased electron temperature at onset, especially not in the E-region.

To conclude the radar results, we see indications that onset reactions in the electrojets at longitudes far separated from magnetic midnight are responses to an imposed electric field, as opposed to conductivity increases that are delayed up to $20 \mathrm{~min}$.

\section{Discussion and conclusion}

The question of the convection electrojet response to substorm onset has only been treated a few times before. Grafe et al. (1987) discovered that the eastward electrojet over Scandinavia experienced strong and immediate intensifications at onset. Opgenoorth and Pellinen (1998) examined abrupt enhancements in the evening sector electrojet, measured by IMAGE. Their results indicated that an electric field was the main agent for these reactions outside the substorm current wedge. In these previous studies only the eastward electrojet on the duskside was searched for reactions. This was because the eastward electrojet is easier to study, being less influenced by particle precipitation and remaining disturbances from the previous night. Also, there are restrictions imposed by the location of instrument networks and the access to data.

This new study, in pursuing a more global and rigorous investigation of the reactions to onset, thus adds the information about the behavior of the westward electrojet which, despite having more complex physics, seems to show similar reactions to substorm onset.

The results indicate a very short time delay between onset and reaction at dawn and dusk, mainly within a few minutes. The distribution of time delays (Fig. 4a, b) is interesting. Although cases with delays close to $6 \mathrm{~min}$ do exist, there are examples of very short delays indeed. The main part of the events have delays less than $4 \mathrm{~min}$, which is thought-provoking since this is much faster than we would expect, considering the known information about spreading mechanisms in the ionosphere.

We expect particle precipitation to change the conductivity in the dawn and dusk sectors, on several different time scales;

1. The substorm current wedge expands with a velocity of a few $\mathrm{km} / \mathrm{s}$ and would be able to reach the dawnand duskside ionosphere in about $20 \mathrm{~min}$ (Opgenoorth and Pellinen, 1998).

2. The energetic electrons injected at magnetic midnight drift eastward and the particles of requisite energy range producing ionospheric Hall conductivity would
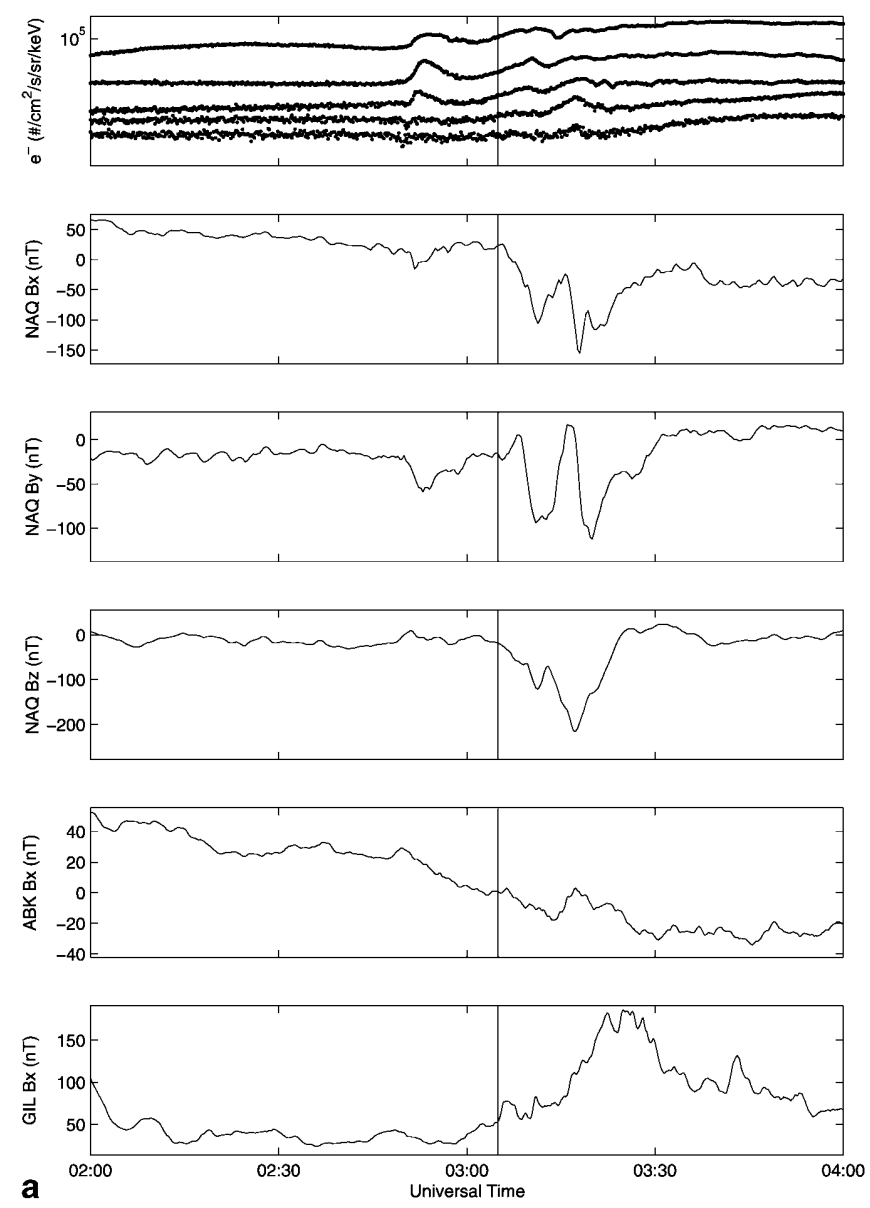

Fig. 5a. 
b

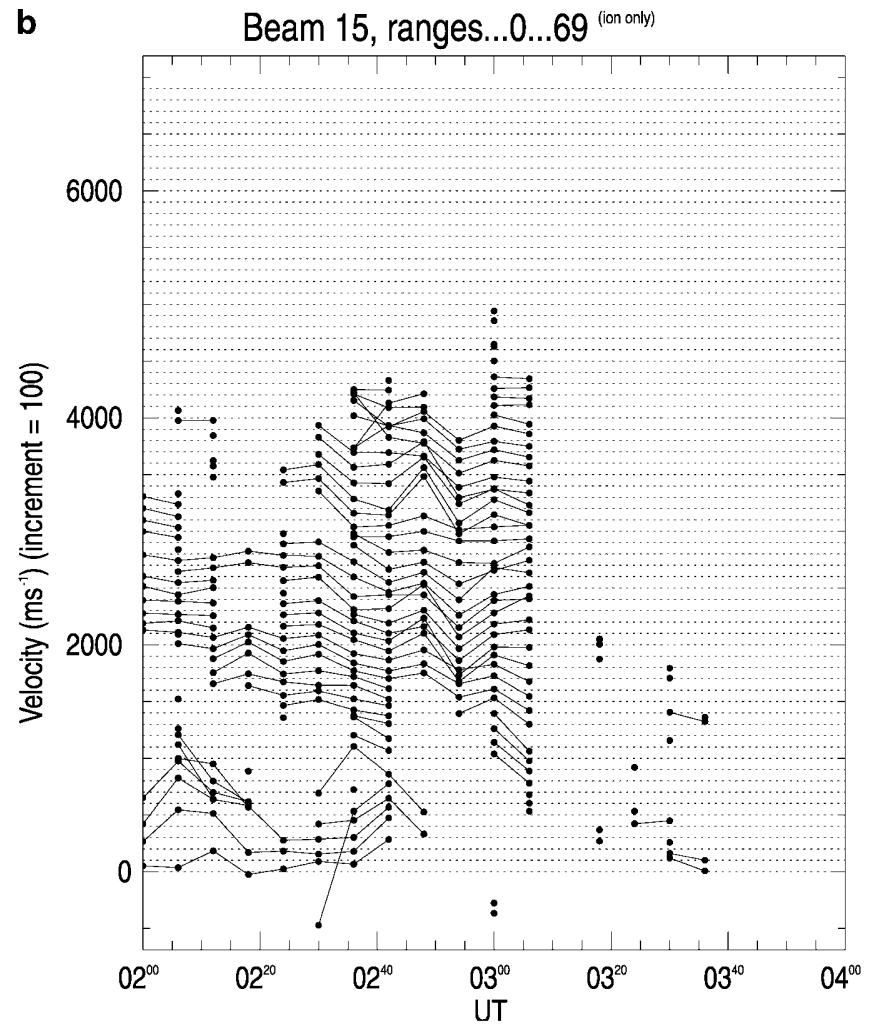

d

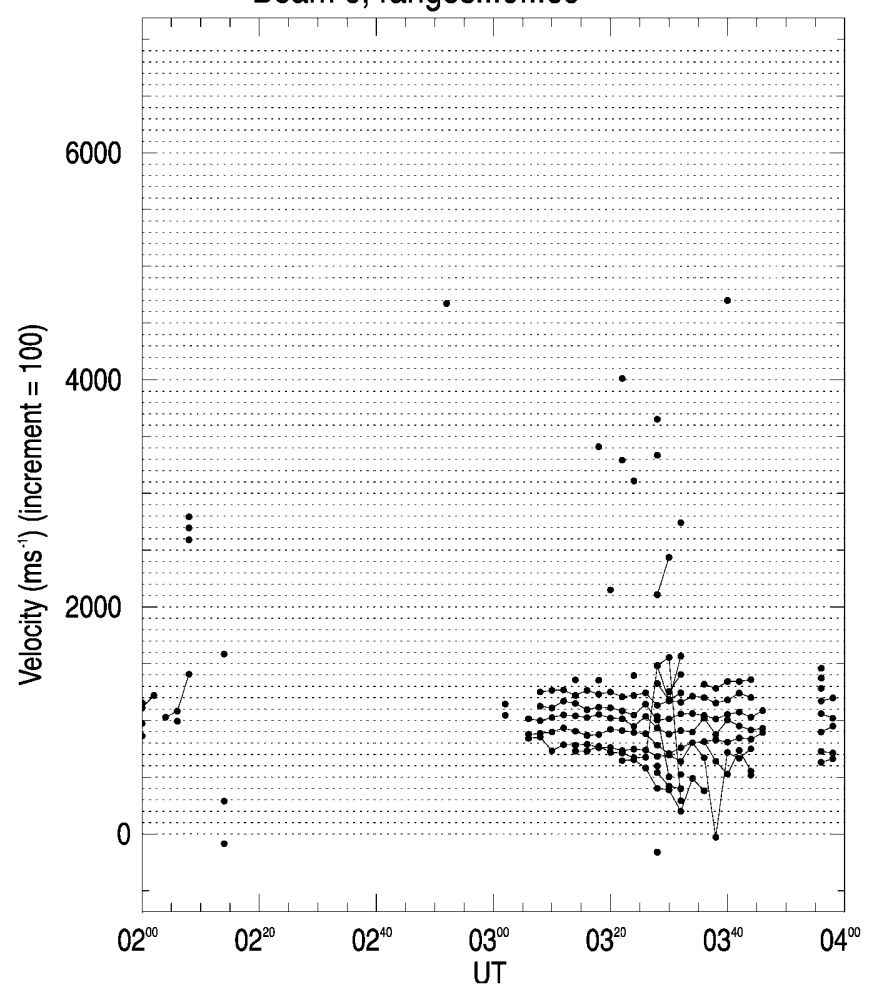

Fig. 5. a April 8 1998. Onset time 03:05 UT, marked by the line in all panels b April 8 1998, SuperDARN Iceland West. Loss of ionospheric scatter in association with the appearance of the substorm current wedge. c April 8 1998, SuperDARN Kapuskasing.

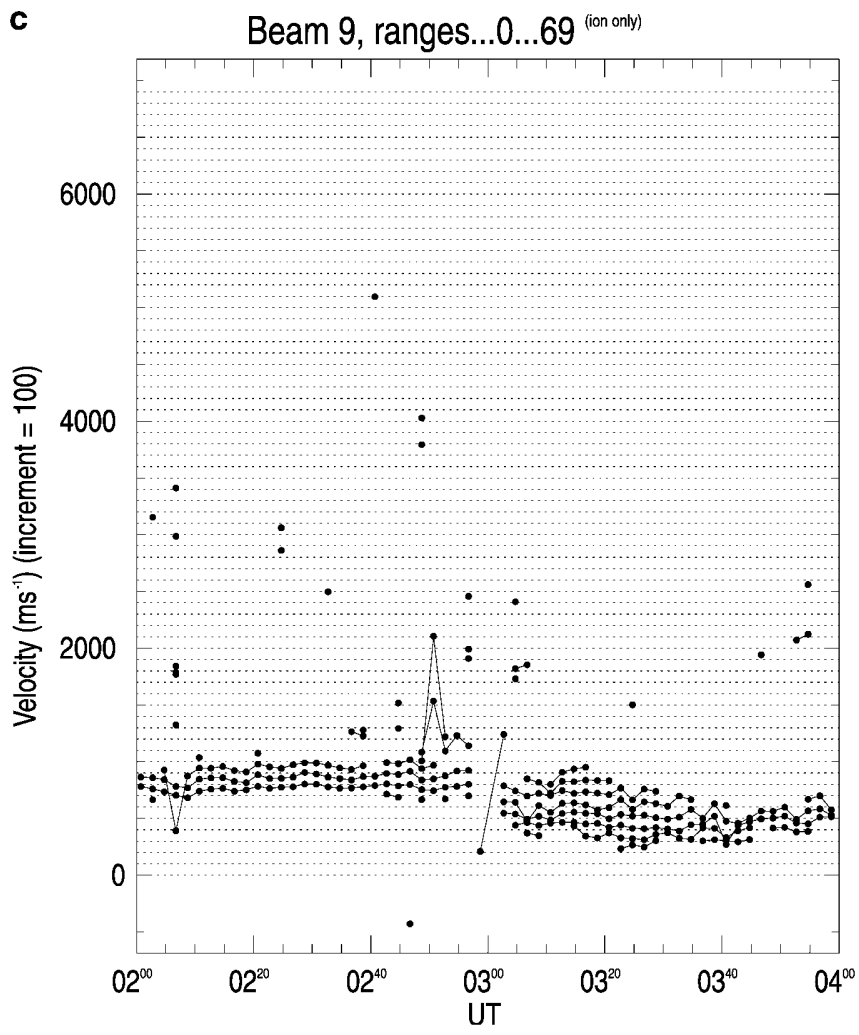

e $\quad$ Beam 9, ranges $1516171819202122^{\text {(ion only) }}$

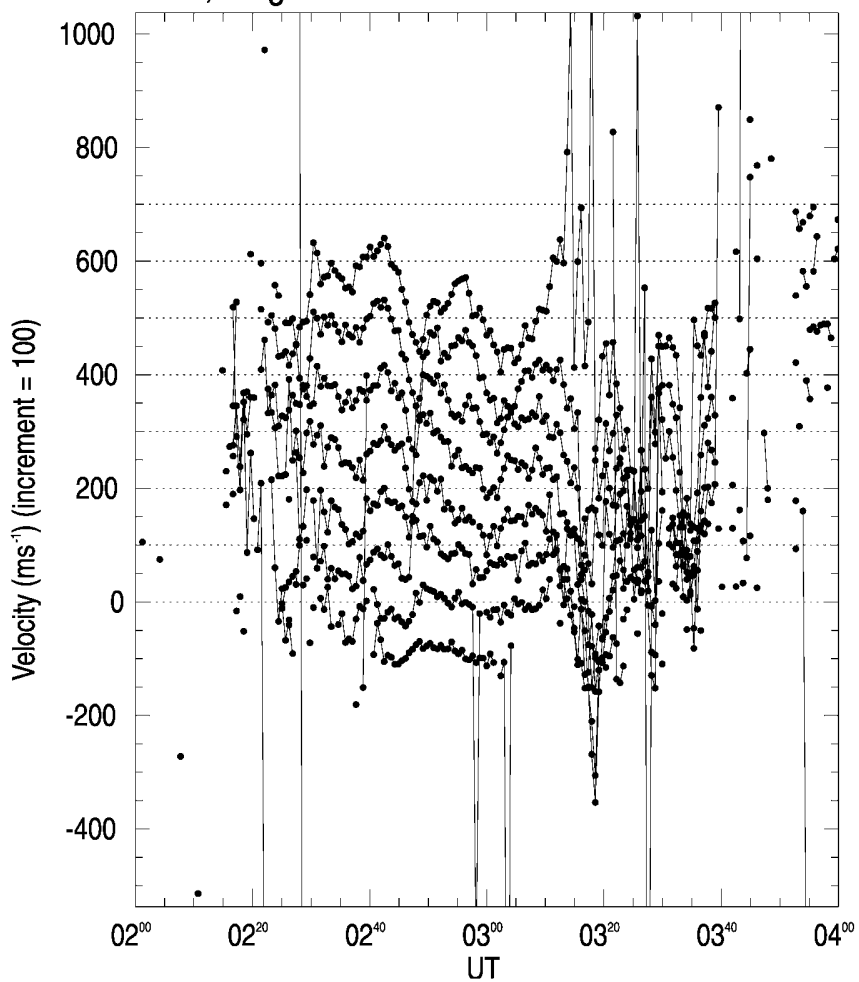

Change of range for the backscatter. d April 8 1998, SuperDARN Saskatoon. Newly appearing scatter. e April 8 1998, SuperDARN CUTLASS Finland 

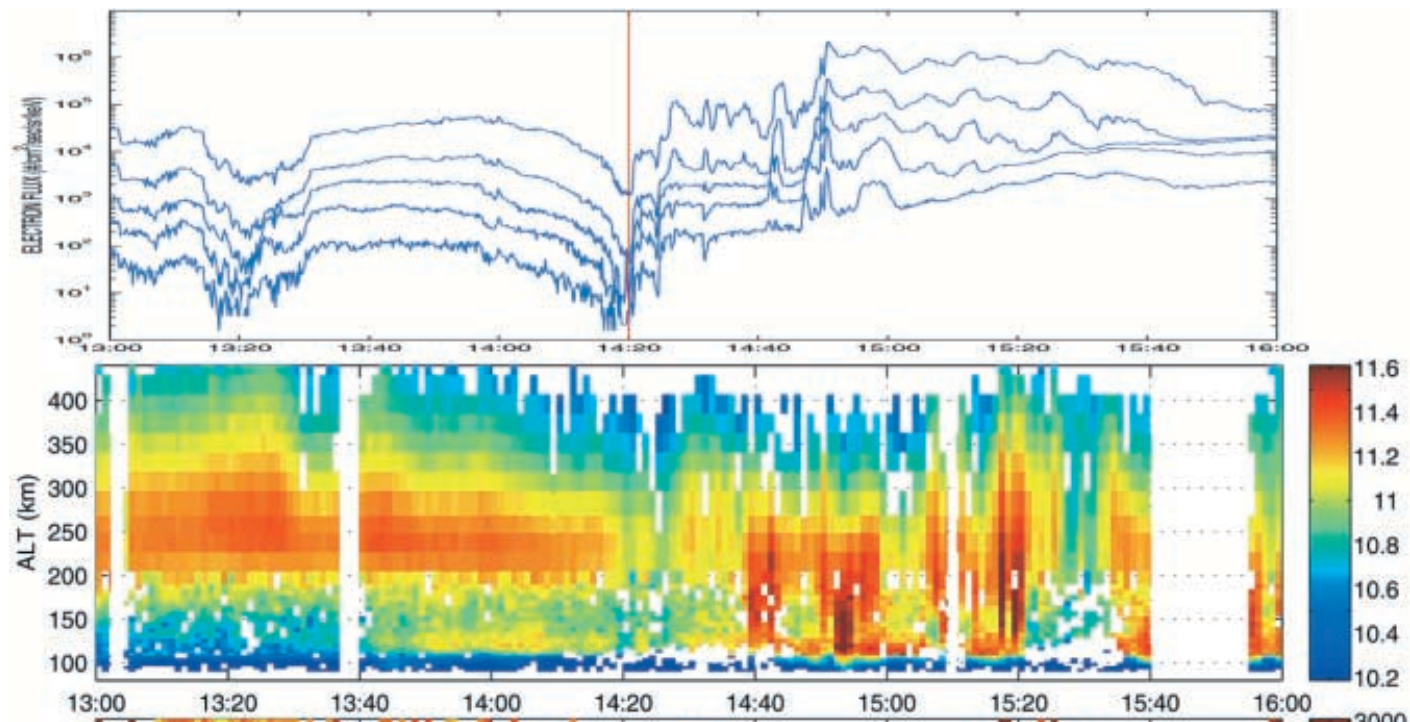

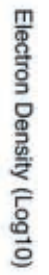

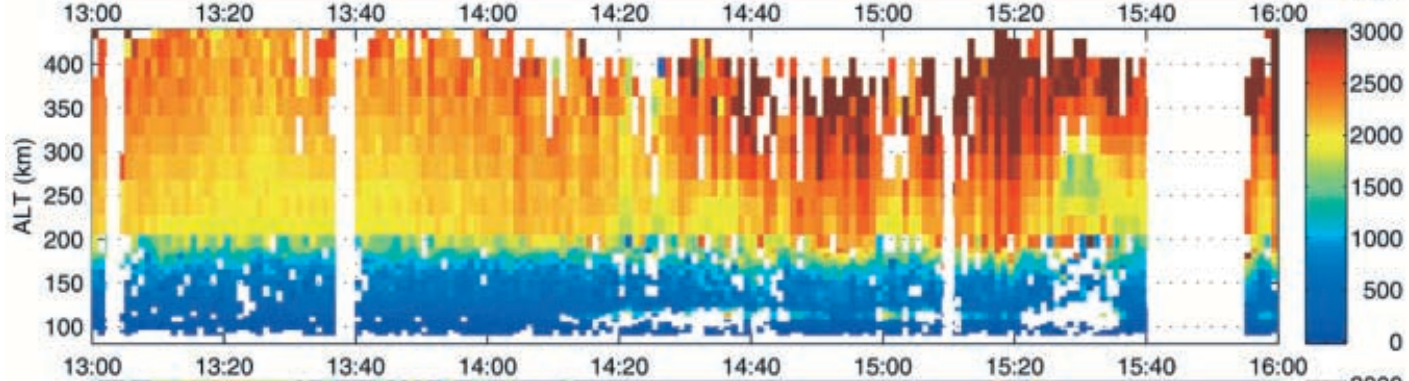

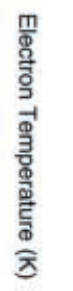

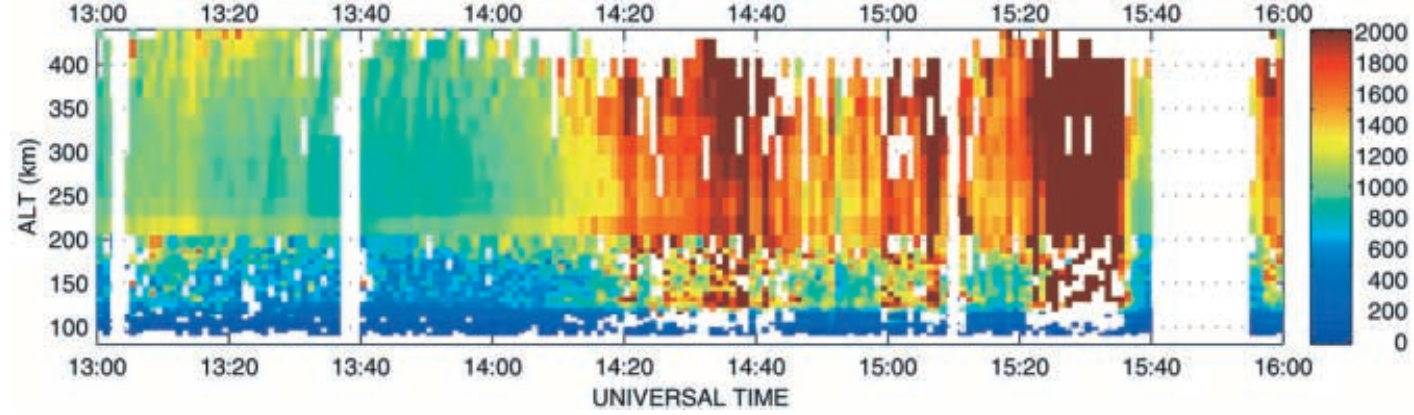

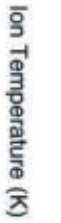

Fig. 6. September 27 1995. Top panel showing electron flux measured by LANL 1994-084. The vertical line at 14:20 UT marks the onset. Following panels displaying electron density and electron/ion tempera-

reach the dusk sector in about $7 \mathrm{~min}$ (Friedel et al., 1996).

3. The auroral horn, as reported by Opgenoorth et al. (1980) and Yahnin et al. (1983), is an intensification of auroral activity moving azimuthally with a velocity of about $10 \mathrm{~km} / \mathrm{s}$ (the mapped magnetosonic velocity in the magnetotail would be about $400 \mathrm{~km} / \mathrm{s}$, Koskinen et al., 1990). It has not been shown how far from magnetic midnight the auroral horn actually propagates, but assuming that it does reach the dusk and dawn sectors it would do so in approximately $4 \mathrm{~min}$.

Changes in the electric field are usually thought to be responses to changes in the magnetospheric convection. A way of transferring information from the current disruption region in the magnetotail to the ionospheric flanks could be caused by magnetosonic waves, spreading azimuthally from the disruption region and then along field lines down to the dawn- and dusk ionosphere. Considering a magnetosonic velocity of $400 \mathrm{~km} / \mathrm{s}$ tures, measured by EISCAT UHF in Tromsø (pointing field-aligned, $\mathrm{cp}-1 \mathrm{k}$ mode). Enhanced ion temperature at 14:20 and increased electron density at 14:39 UT

the azimuthal spreading alone would require nearly $2 \mathrm{~min}$. The total spreading time would therefore be of the same magnitude as the auroral horn, i.e., approximately 4 min.

Ionospheric radar studies presented here show that the fast responses in the electrojets, some of them faster than the $4 \mathrm{~min}$ stated, are clearly controlled by an imposed electric field. Opgenoorth and Pellinen (1998) also found a small contribution from precipitating particles, but at a delay of the order of several minutes. This delayed precipitation enhancement can be explained by the auroral horn feature mentioned previously.

How could the short time scale of these electrojet reactions be explained? The findings presented, with fast reactions at dawn and dusk at substorm onset, imply that a substorm is indeed a global phenomenon in the magnetosphere, as suggested by Baker et al. (1998). Usually the region of initial substorm activity, as seen 
from the Earth, is thought to be both longitudinally and latitudinally limited in space near magnetic midnight, but this might not be an adequate picture. For both the dusk- and dawnside regions, the reactions were visible at several magnetometer stations over a longitudinally and latitudinally extended area, implying the observation of a large-scale phenomena in the magnetosphere.

There is a problem since we do not know the initial substorm onset location in the tail. The CD model predicts it to be about about $10 \mathrm{R}_{E}$ downtail, the NENL model $20-30 \mathrm{R}_{E}$ downtail. Depending on which model is considered, the explanations would have to differ.

We first assume that the latter theory describes the onset correctly, so that a NENL forming in the tail causes Earthward fast flows or a large-scale convection surge. The current disruption is a localized process near magnetic midnight, due to some local instability in the cross-tail current. Assuming that an instability has established close to critical level during the growth phase, the fast flows divert around the Earth, causing a compressional pulse into the inner magnetosphere, which might trigger the current disruption in the localized area at midnight. Outside the instability region the compressional pulse continues Earthward, resulting in an imposed electric field in the flanks of the ionosphere. This imposed electric field would then be responsible for the reactions of the auroral electrojets, while the field-aligned currents supporting the substorm electrojet would mainly be controlled by the increased conductivity on the nightside ionosphere. With suitable satellite positions it should be possible to detect the Earthward flows and the subsequent compressional pulse, and relate these events to the observed substorm process.

If we assume on the other hand that the CD preceeds the NENL, we would have to find a mechanism for the localized instablility at magnetic midnight to produce a reaction in the ionosphere at longitudes far away from midnight. According to the CD model the disturbance would start close to $10 \mathrm{R}_{E}$ and spread azimuthally as well as tailward, creating the neutral line. The azimuthal expansion would lead to information being mediated via the field lines to the dawn and dusk ionosphere, with a minimum travel time of approximately 4 min (estimation based on the mapped magnetosonic velocity of the auroral horn, see Koskinen et al., 1990), which is not supported by our observations.

The main problem, and the most important factor in this study, is the timing of the onset. Here we looked at a combination of particle injections and magnetic bays to make a good estimate. One conclusion was that satellite data on its own would have required more detailed work and probably reduced the number of events, since these point-like measurements are dependent on the location of the instrument. Furthermore, a good method of extrapolation is needed when determining the onset time from dispersed injections (Friedel et al., 1996). The magnetometers have an advantage in integrating over a large area, thereby they are not as dependent on the exact onset location as the satellites are. Even so the distance between the magnetometer stations and the substorm current wedge can be large, causing some uncertainities in timing.

The timing problem can be understood from the several examples found with negative time delays, that is, a distinct gradient change is observed in the dawn and dusk magnetograms before the actual onset. For a few of these events we conclude that the onset time has been chosen to be too late. Although the first example shown here (Fig. 2) displays a clear reaction in MARIA that preceeds the onset by almost $2 \mathrm{~min}$, and yet here we believe we have a reliable onset time. This discrepancy could be solved by considering that the term "reaction" is somewhat misleading. The Eartward flow description of substorms can actually account for the negative time delays. The compressional pulse caused by the fast flows might not trigger the CD instantaneously, so with a delay of 1-2 min of the appearance of the substorm current wedge the electric field, also caused by the compressional pulse, could indeed be detected earlier at the ionospheric flanks.

Clearly the negative time delays must be investigated further. If we used some method of extrapolation to obtain onset times from satellite data and added information from other substorm indicators, we assume that some of the negative time lags would disappear.

Preferably one would use as many substorm indicators as possible; particle injections at geosynchronous orbit, magnetic bays due to the substorm current wedge, Pi2 pulsations, and optical instruments to study auroral breakup and monitor the appearance and expansion of the current wedge. As we saw in the example with SuperDARN, changes in coherent scatter for radars located underneath the substorm current wedge can also serve as an indicator.

When using several indicators for timing onsets, there is the question of which indicator is the most reliable. Yeoman et al. (1994) have investigated the correlation between particle injections and $\mathrm{Pi} 2$ pulsations as substorm indicators, with the conclusion that they are correlated to a high level, but with a small percentage of events where, for some unknown reason, injections occur without pulsations and vice versa. They looked for events, where injections and pulsations occurred near-simultaneously, within $10 \mathrm{~min}$ for dispersionless and $20 \mathrm{~min}$ for dispersed injections. Earlier studies by Kamide and McIlwain (1974) and Bargatze et al. (1987), reveal that particle injections at geosynchronous orbit are delayed by about $6 \mathrm{~min}$, compared to Pi2 pulsations in the auroral zone. Kamide and McIlwain (1974) suggested two explanations for this delay, based on possible errors in the definition of onset time in both magnetometer and satellite data, which would likely place the onset time somewhat too late. Bargatze et al. (1987) explained the time delay with a physical picture of different travel times for particles and waves coming from the NENL, naturally leading to a time delay between the onset signatures.

Reeves et al. (1996a) compared injection timing at different L-shells by using CRRES EPAS and a LANL geostationary satellite, and found a radially Earthward propagation velocity of $24 \mathrm{~km} / \mathrm{s}$ of the injection region. 
Extrapolation gives a source region of injected particles within a few $\mathbf{R}_{E}$ of geostationary orbit. So unless the source region is at $6.6 \mathrm{R}_{E}$, the delay between substorm onset detected on ground and injection detected at geostationary orbit could be explained by the propagation time for the injected particles, naturally leading to a delay of a few minutes.

Liou et al. (1998) concluded that auroral breakup, monitored by the Polar spacecraft, is the most reliable onset identifier among auroral activity, magnetic bays and $\mathrm{Pi} 2$ pulsations. They found that $\mathrm{Pi} 2 \mathrm{~s}$ lag behind breakups by 1-3 $\mathrm{min}$ and the negative bays are visible only when the auroral bulge has moved overhead of the station. They only used the $x$-component for the magnetic bays, though, and as we mentioned, a more accurate timing can be achieved by studying all three components (Opgenoorth et al., 1980). Sometimes the onset can be detected earlier in the $z$-component, depending on the location of the substorm current wedge relative to the magnetometer station.

Liou et al. (1999) continued their work by two case studies, adding data from dispersionless injections at geostationary orbit, measured by LANL, and auroral kilometric radiation (AKR), measured by the Polar spacecraft. They argued that magnetic bays can be delayed by up to tens of minutes, even if the highlatitude magnetometer is in the midnight sector. The Pi2s were delayed by $1 \mathrm{~min}$ compared to auroral breakup, consistent with their previous results. The dispersionless injections lagged the breakup by 1-3 mins. The AKR was more difficult to evaluate due to the location of Polar, and no definitive conclusions could be drawn.

We do not know of any statistical comparison study between particle injections and magnetic bays, which we feel would be justified, since both methods are frequently used in timing of onsets and there is a nearly continous supply of data. In such a study all three magnetic components should be examined and a number of magnetometer stations used, since different substorms have different degrees of disturbance, hence different latitudinal (and longitudinal) onset location.

The relation between different substorm indicators might be a fundamental clue to the onset process, even though they seem to be linked in a complicated manner, depending on ionospheric and magnetospheric parameters in a way not completely understood. The main problem is clearly the relative timing of these indicators. Case studies are dependent on the location of the instruments and might not reveal the "true" temporal order of the indicators.

We have reported on the convection electrojets' response to substorm onset. We have shown that there are nearly instantaneous reactions in the electrojets at dawn and dusk. The responses, caused by imposed electric fields, can be explained by the fast flows in the NENL substorm model. The work has furthermore illustrated the importance of using combinations of instruments over a large geographical area in order to improve our understanding of magnetospheric physics.
Acknowledgements. The satellite data was provided by the Los Alamos National Laboratory (LANL). The Greenland magnetometer data was provided by the Danish Meteorological Institute (DMI). The IMAGE magnetometer data were collected as a Finnish - German - Norwegian - Polish - Russian - Swedish project. The PI institute since 1996 is the Finnish Meteorological Institute (FMI). The MARIA magnetometer data is the property of the Canadian Space Agency (CSA). The authors thank the PIs of SuperDARN radars (J.-P Villain, G. Sofko, R. Greenwald, M. Lester) and their respective teams for supplying the data. The Director of EISCAT and all the EISCAT staff are thanked for the operation of EISCAT and supplying the data. The EISCAT association is supported by the national scientific agencies of Finland, France, Germany, Norway, Sweden, Japan and the United Kingdom. The authors also wish to thank S. Buchert (at STEL, Nagoya, Japan) for notifying the authors of the particular EISCAT event data.

Topical Eidtor M. Lester thanks T. Yeoman for his help in evaluating this paper.

\section{References}

Baker, D. N., T. I. Pulkkinen, V. Angelopoulus, W. Baumjohann, and R. L. McPherron, Neutral line model of substorms: past results and present view, J. Geophys. Res., 101 (A6), 12 975, 1996.

Baker, D. N., T. I. Pulkkinen, J. Büchner, and A. J. Klimas, Substorms: a global magnetospheric instability, in Substorms-4, Eds S. Kokubun and Y. Kamide, Co-publication: Terra Scientific Publishing Company (Tokyo)/Kluwer Academic Publishers (Dordrecht) 231, 1998.

Bargatze, L. F., D. N. Baker, and R. L. McPherron, Superposed epoch analysis of magnetospheric substorms using solar wind, auroral zone, and geostationary orbit datasets, in Magnetotail physics, Ed. T. Y. Lui, John Hopkins University Press, Baltimore, 163, 1987.

Folkestad, K., T. Hagfors, and S. Westerlund, EISCAT: an updated description of technical characteristics and operational capabilities, Radio Sci., 18, 867, 1983.

Friedel, R. H. W., A. Korth, and G. Kremser, Substorm onsets observed by CRRES: determination of energetic particle source regions, J. Geophys. Res., 101, 13 137, 1996.

Grafe, A., R. J. Pellinen, W. Baumjohann, and M. Vallinkoski, Development of the auroral electrojets on March 16, 1978: an Event study, Geophysica, 23, 113, 1987.

Greenwald, R. A., K. B. Baker, J. R. Dudeney, M. Pinnock, T. B. Jones, E. C. Thomas, J.-P. Villain, J.-C. Cerisier, C. Senior, C. Hanuise, R. D. Hunsucker, G. Sofko, J. Koehler, E. Nielsen, R. Pellinen, A. D. M. Walker, N. Sato, and H. Yamagishi, DARN/SUPERDARN, a global view of the dynamics of highlatitude convection, Space Sci. Revi., 71, 761, 1995.

Kamide, Y., and W. Baumjohann, Magnetosphere - ionosphere coupling, Springer Berlin Heidelberg New York, 1993.

Kamide, Y., and S. Kokubun, Two-component auroral electrojet: importance for substorm studies, J. Geophys. Res., 101 (A6), 13 027, 1996.

Kamide, Y., and H. W. Kroehl, Auroral electrojet activity during isolated substorms at different local times: a statistical study, Geophys. Res. Lett., 21 (5), 389, 1994.

Kamide, Y., and C. E. McIlwain, The onset time of magnetospheric substorms determined from ground and synchronous satellite records, J. Geophys. Res., 79 (31), 4787, 1974.

Koskinen, H. E. J., T. I. Pulkkinen, and R. J. Pellinen, Mapping of the auroral horn into the magnetotail, Planet. Space Sci., 38, $1179,1990$.

Liou, K., C.-I. Meng, T. Y. Lui, P. T. Newell, M. Brittnacher, G. Parks, and M. Nosé, A fresh look at substorm onset identifiers, in Substorms-4, Eds. S. Kokubun and Y. Kamide, Co-publication: Terra Scientific Publishing Company (Tokyo)/Kluwer Academic Publishers (Dordrecht) 249, 1998. 
Liou, K., C.-I. Meng, T. Y. Lui, P. T. Newell, M. Brittnacher, G. Parks, G.D. Reeves, R.R. Anderson, and K. Yumoto, On relative timing in substorm onset signatures, J. Geophys. Res., 104 (A10), 22 807, 1999.

Lühr, H., A. Aylward, S. C. Buchert, A. Pajunp, T. Holmboe, and S. M. Zalewski, Westward moving dynamic substorm features observed with the IMAGE magnetometer network and other ground-based instruments, Ann. Geophysicae, 16, 425, 1998.

Lui, A. T. Y., Current disruption in the Earth's magnetosphere: observations and models, J. Geophys. Res., 101 (A6), 13 067, 1996.

Ohtani, S., F. Creutzberg, T. Mukai, H. Singer, A.T.Y. Lui, M. Nakamura, P. Prikryl, K. Yumoto, and G. Rostoker, Substorm onset timing: the December 31, 1995, event, $J$. Geophys. Res., 104 (A10), 22 713, 1999.

Opgenoorth, H. J., and R. J. Pellinen, The reaction of the global convection electrojets to the onset and expansion of the substorm current wedge, in Substorms-4, Eds. S. Kokubun and Y. Kamide, Co-publication: Terra Scientific Publishing Company (Tokyo)/Kluwer Academic Publishers (Dordrecht) 663, 1998.

Opgenoorth, H. J., R. Pellinen, H. Maurer, F. Küppers, W. Heikkila, K. U. Kaila, and P. Tanskanen, Ground-based observations of an onset of localized field-aligned currents during auroral breakup around magnetic midnight, J. Geophys., 48, 101, 1980.

Reeves, G. D., M. G. Henderson, P. S. McLachlan, R. D. Belian, R. H. W. Friedel, and A. Korth, Radial propagation of substorm injections, Proc. ICS-3, Versailles, France, 579-584, 1996a.

Reeves, G. D., R. D. Belian, T. C. Cayton, R. A. Christensen, M. G. Henderson, and P. S. McLachlan, Los Alamos space weather data products: on line and on time, Proc. Third International
Conference on Substorms (ICS-3), Versailles, France, 689, 1996b.

Reeves, G. D., New perspectives on substorm injections, Proc. ICS-4, Hamanako Japan, 1998.

Rostoker, G., Phenomenology and physics of magnetospheric substorms, J. Geophys. Res., 101, 12 955, 1996.

Rostoker, G., J. C. Samson, F. Creutzberg, T. J. Hughes, D. R. McDiarmid, A. G. McNamara, A. Vallance Jones, D. D. Wallis, and L. L. Cogger, CANOPUS - a groundbased instrument array for remote sensing the high latitude ionosphere during the ISTP/GGS program, Space Sci. Rev., 71, 743, 1995.

Shiokawa, K., W. Baumjohann, G. Haerendel, G. Paschmann, J. F. Fennel, E. Friis-Christensen, H. Lühr, G. D. Reeves, C. T. Russell, P. R. Sutcliffe, and K. Takahashi, High-speed ion flow, substorm current wedge, and multiple Pi2 pulsations, J. Geophys. Res., 103 (A3), 4491, 1998.

Syrjäsuo, M. T., T. I. Pulkkinen, P. Janhunen, A. Viljanen, R. J. Pellinen, K. Kauristie, H. J. Opgenoorth, S. Wallman, P. Eglitis, P. Karlsson, O. Amm, E. Nielsen, and C. Thomas, Observations of substorm electrodynamics using the MIRACLE network, in Substorms-4, Ed. S. Kokubun and Y. Kamide, Co-publication: Terra Scientific Publishing Company (Tokyo)/Kluwer Academic Publishers (Dordrecht) 111, 1998.

Yahnin, A. G., V. A. Sergeev, R. J. Pellinen, W. Baumjohann, K. U. Kaila, H. Ranta, J. Kangas, and O. M. Raspopov, Substorm time sequence and microstructure on 11 November 1976, J. Geophys., 53, 1821983.

Yeoman, T. K., M. P. Freeman, G. D. Reeves, M. Lester, and D. Orr, A comparison of midlatitude $\mathrm{Pi} 2$ pulsations and geostationary orbit particle injections as substorm indicators, J. Geophys. Res., 99 (A3), 4085, 1994. 